\title{
Kajian Doa Puasa Bagi Pertumbuhan Spiritual Di Jemaat GKII Tanjung Belimbing Kalimantan Utara
}

\author{
Alfrilionita Farah Sulfriyanti, Leonard Sumule
}

\begin{abstract}
Abstrak
Doa puasa adalah suatu hubungan yang dilakukan oleh orang Kristen untuk berkomunikasi kepada Tuhan dengan cara menyiapkan diri secara pribadi agar kita dapat menfokuskan tujuan untuk lebih dekat lagi dengan Tuhan. Karena dalam doa puasa membawa kita untuk berserah dan mengucap syukur atas penyertaan Tuhan dalam kehidupan. Doa puasa merupakan pertama, berdasarkan penelitian penulis, maka disadari bahwa doa dan puasa adalah komunikasi yang dilakukan antara orang percaya dengan Tuhan dan menfokuskan hati serta pikirannya kepada Tuhan dengan mampu menahan segala keinginan-keinginan daging.Kedua, dampak doa dan puasa merupakan salah satu bagian yang penting bagi orang Kristen yang perlu terus dilakukan di jemaat GKII Tanjung Belimbing. Ketiga, mengenai tantangan-tantangan yang dihadapi oleh jemaat dalam melakukan doa puasa, maka jemaat perlu mampu melawan setiap tantangan-tantangan dalam melakukan doa puasa dengan meminta hikmat dari Roh Kudus. Keempat, fungsi seorang dari hamba Tuhan menolong dan memberikan motivasi kepada jemaat untuk terus giat melakukan doa puasa.Kelima, penting bagi orang Kristen melakukan doa dan puasa untuk pertumbuhan spiritual.
\end{abstract}

Kata-kata Kunci: Doa Puasa, Pertumbuhan, Spiritual.

\section{Pendahuluan}

\section{Latar Belakang Masalah}

Kehidupan seorang Agamawi dapat dilihat dengan pertumbuhan spiritualnya yang baik itu kepada Allah, sesama dan pelayanan. Pertumbuhan spiritual dapat dilihat dengan bagaimana orang percaya memulai kehidupannya dengan doa. Disiplin rohani harus ditunjukkan oleh setiap orang Kristen. Yang menjadi permasalahan orang Kristen saat ini adalah mulai meninggalkan kehidupan doa puasa yang sebenarnya sangat penting dilakukan. Sesungguhnya kehidupan doa puasa dapat membangun spiritual orang percaya saat ini. Menurut Stephen Tong:

Apakah kebangunan terjadi karena doa manusia? Kebangunan adalah anugerah Tuhan, maka bukan karena kita berdoa lalu Tuhan mengadakan kebangunan, dan bila kita tidak berdoa maka Tuhan tidak mengadakan kebangunan. Kalau demikian, bukankah ini merupakan pernyataan yang bersifat kontradiktif? Bukankah sejarah bungkam dan tidak pernah mencatat kebangunan yang tidak dimulai dengan doa? berarti kita berdoa dulu, baru kebangunan terjadi. Kalau begitu bukankah doa yang mengakibatkan kebangunan? Berdoa dahulu, baru terjadi kebangunan, kalau tidak berdoa berarti tidak akan terjadi kebangunan. Secara urutan waktu dan secara tertulis memang betul, berdoa dahulu baru terjadi kebangunan. Jadi, bukankah kebangunan merupakan hasil doa kita? 
Kita memberi perintah kepada Allah, dan Allah menaatinya? Tidak. Karena doa yang benar sudah merupakan permulaan dari kebangunan yang sesungguhnya. Artinya, anugerah Tuhan selalu mendahului reaksi manusia.Kebangunan rohani seorang Kristen dapat kita lihat dari kehidupan doa puasa yang dilakukan. Doapuasa adalah syarat yang muktlak dilakukan agar kita mengalami secara pribadi kebangunan rohani itu. ${ }^{1}$

Berbicara tentang doa puasa banyak akan berpikir bahwa itu hanya dilakukan oleh pendeta atau hamba Tuhan, penginjil serta para pelayan yang melayani di gereja menganggap itu adalah tugas mereka untuk berdoa dan berpuasa untuk jemaat. Jemaat pada umumnya hanya menganggap mereka hanya perlu datang ke gereja untuk beribadah, menyanyi, serta dengar Firman Tuhan. Jadi, jemaat mengira bahwa doa puasa bukanlah tugas mereka juga. Ini dikarenakan jemaat belum mendapatkan pengajaran yang baik dan pengertian yang baik tentang doa dan puasa. Doa puasa ditujukan untuk orang Kristen. Orang Kristen perlu doa puasa karena perjuangan kita bukanlah melawan darah dan daging, tetapi melawan pemerintah-pemerintah di udara. Perlu sekali orang percaya melakukan doa puasa, karena Yesus terlebih dahulu menunjukkan hal ini kepada orang percaya. Doa puasa perlu dilakukan oleh semua orang Kristen, bukan hanya dilakukan oleh orang-orang tertentu saja. Ini adalah tugas semua orang Kristen.

Dalam doa puasa harus kembali kepada kesadaran diri sendiri tentang apa yang harus kita perbuat? Waktu seseorang percaya Kristus, inilah yang harus dilakukan. Lewat doa puasa ada kekuatan dan kuasa yang Tuhan berikan. Doa puasa membuat orang percaya memiliki banyak waktu dengan Tuhan. Doa puasa membuat lebih berfokus kepada Tuhan. Doa puasa bukan hanya berdoa untuk diri sendiri, tetapi juga berdoa berpuasa buat orang lain.

Memang banyak yang akan dialami oleh orang Kristen ketika mereka betul-betul bertekun dalam doa puasa. Banyak pengalaman rohani yang akan dialami secara tidak langsung dengan Allah. Doa puasa bukan hanya sekadar untuk menahan hawa nafsu dari makan dan minum tetapi doa puasa mengajarkan orang percaya banyak hal. Doa puasa dapat menahan kita dari segala hawa nafsu dan lewat doa puasa ada pengendalian diri yang akan terlihat secara langsung. Berpuasa adalah ketetapan Allah. Puasa berarti kita sebagai orang percaya merendahkan diri di hadapan Tuhan.

Yang menjadi masalah orang Kristen tidak mau untuk berdoa karena pemahaman tentang doa yang salah karena menganggap doa sebagai hal yang biasa untuk dilakukan sebagai rutinitas yang seperti biasa karena saya orang Kristen jadi wajar saja saya melakukan hal itu. Kalau orang Kristen tidak mengerti yang sebenarnya tentang doa, dia tidak akan berdoa. Doa adalah pengakuan kita kepada Allah. Atau mungkin juga orang Kristen yang pemahaman tentang doa itu sudah benar, tetapi malas untuk dilakukan karena berbagai faktor yang dilakukan seperti rutinitas yang dilakukan dan membuat lelah. Atau berdoa dengan asalasalan dan berdoa dengan seperlunya saja

Orang Kristen dapat berdoa di mana dan kapan saja. Namun, mengapa begitu banyak orang Kristen sangat sulit sekali menjalin komunikasi yang intim dengan Tuhan. Sebagai anak-anak Allah, tidak ada hal yang lebih penting atau pekerjaan yang lebih penting selain doa dan puasa.

${ }^{1}$ Stephen Tong, Roh Kudus, Doa DanKebangunan (Surabaya: Momentum, 2006), 112, 113. 
Seperti yang dituliskan Gondowijoyo, "Doa bukanlah apa yang kita lakukan sebelum berangkat bekerja, tapi doa sebenarnya adalah pekerjaan. Sebuah hubungan pribadi yang intim dengan Bapa kita yang terkasih adalah alasan kita untuk hidup dan merupakan pusat segalanya." Doa sungguh-sungguh merupakan kesiapan manusia untuk mendengar, menuruti, dan menaati sehingga hubungan yang paling dasar dengan Allah dapat lebih disadari sepenuhnya, hal itu dapat menjelaskan mengapa doa dipandang sebagai inti agama, serta sumber terangnya jiwa kepada Allah. Dalam doa orang Kristen mulai melihat diri sendiri seperti Allah memandangnya dan orang percaya melihat Allah sebagaimana Ia ada. Dalam doa orang percaya mengakui bahwa bukan kita yang memegang kendali. Tidak berdoa berarti menaruh nasib kita ke dalam tangan kita sendiri memalsukan diri kita yang sebenarnya sebagai ciptaan yang tergantung dan menyangkal Allah sebagai Pribadi yang berdaulat. Kedekatan hubungan dengan Allah ditandai dengan kehidupan doa. ${ }^{2}$ Orang Kristen harus melihat kehidupannya apakah hidup terikat dengan doa, karena Tuhan sendiri sampai saat ini masih terikat dengan doa. Pekerjaan terbesar orang Kristen adalah doa. ${ }^{3}$

Hubungan yang benar dan intim bersama Tuhan didasarkan pada pertobatan yang sejati dan perjumpaan pribadi dengan Tuhan. Lewat perjumpaan pribadi dengan Tuhan, membawa pertumbuhan rohani yang baik, dengan waktu saat bersekutu dengan Tuhan melalui doa puasa. Hubungan yang baik dengan Tuhan juga akan berdampak baik dengan hubungan kita dengan sesama. Hubungan yang baik dengan Tuhan akan membawa kita bersandar penuh kepada kuasa Roh Kudus yang akan senantiasa menuntun kita bertumbuh dalam kekudusan. ${ }^{4}$

Spiritualitas adalah disiplin rohani, atau hubungan pribadi dengan Allah. Spiritualitas orang Kristenadalah disiplin rohani atau hubungan pribadi dengan Allah yang dilakukan secarakonsisten oleh seorang pelayanan Tuhan atau orang yang terpanggil untuk melayani Tuhan dalam seluruh aspek kehidupannya, baik secara formal maupun non-formal. Tuhan Yesus menggabungkan puasa dengan doa. Puasa tidak bisa dipisahkan dengan doa. Doa menjadi kesatuan dengan puasa. Puasa tidak dapat dipisahkan dengan doa, keduanya saling berkaitan satu dengan yang lainnya. Orang Kristen yang berdoa kadang-kadang harus berpuasa. Jika kita dituntun oleh Allah, maka dalam doa puasa orang percaya menggunakan waktu satu hari penuh untuk bersekutu dengan Tuhan secara pribadi dan membaca Firman Tuhan. $^{5}$

Doa puasa sangat penting dalam pertumbuhan spiritual kekristenan. Dalam Perjanjian Lama yang terdapat di kitab Imamat 16:31, mengatakan: "Hari itu harus menjadi sabat, hari perhentian penuh, bagimu dan kamu harus merendahkan diri dngan berpuasa. Itulah suatu ketetapan untuk selama-lamanya."Doa puasa mengajarkan orang percaya bagaimana sepenuhnya menyerahkan setiap persoalan atau pergumulan. Banyak hal akan terjadi ketika melakukan doa puasa. Hal-hal yang secara manusia itu tidak mungkin terjadi,

\footnotetext{
2J.H. Gondowijoyo, Membangun Keintiman dengan Bapa (Yogyakarta: Penerbit ANDI, 2011), vii, ix.

3..H. Gondowijoyo, Membangun Keintiman dengan Bapa (Yogyakarta: Penerbit ANDI, 2011),x.

${ }^{4}$ Rosyanthi Ferayanthi Bambarehi \& Ivone Bonyadone Palar, "Formasi Rohani Seorang Pelayan Anak Dalam Penunjang Efektivitas Pelayanan,"Jurnal Jaffray 9, no. 2 (2011): 7, diakses 20 Februari 2018, http://www.teliti.com/id/publications/137641/formasi-rohani-seorang-pelayan-anak-dalam-menunjangefektivitas-pelayanan\&hl=id-ID.

5JermiaDjadi, "Spiritualitas Seorang Pelayan Tuhan,"Jurnal Jaffray 10, No. 1 (2012):110-117, diakses 20 Februari 2018, hhtp://www.academia.edu/7737384/Jurnal_Jermia_Djadi_6.
} 
namun ketika orang percaya membawa semua itu ke dalam doa puasa maka akan melihat bahwa kuasa kedaulatan Allah sungguh nyata kita rasakan pribadi lepas pribadi.

Menurut pengamatan penulis, gereja GKII Tanjung Belimbing adalah gereja yang visioner. Gereja ini memiliki salah satu program yang sangat baik yaitu doa puasa. Doa puasa dilakukan setiap awal bulan dalam jemaat ini. Doa puasa ini dimaksudkan agar setiap jemaat dapat ikut ambil bagian di dalamnya. Dalam memulai pelayanan, ibadah dan mendoakan pergumulan atau beban setiap jemaat dalam gereja ini setiap bulan seluruh jemaat diwajibkan untuk ikut serta dalam doa puasa. Ini adalah program gereja yang sangat baik, karena menurut pengamatan penulis gereja inilah satu-satunya yang baru pertama kali yang melakukan doa puasa setiap bulannya di dalam lingkup GKII yang ada di Kabupaten Malinau, Kalimantan Utara. Tetapi yang menjadi kendala juga banyak yang menghambat jemaat untuk datang ikut dalam doa puasa yang diadakan gereja ini.

Dalam penjelasan di atas menjelaskan bahwa betapa pentingnya doa puasa di dalam jemaat di mana doa puasa diajarkan kepada jemaat. Doa puasa sangatlah baik untuk jemaat disiplin dalam kerohanian. Doa puasa melatih jemaat untuk bertumbuh dalam spiritual. Penulis sering mengamati jemaat-jemaat lebih cenderung banyak datang untuk ibadah umum dibandingkan dengan ikut dalam ibadah doa puasa oleh sebab itu gereja dan para hambahamba Tuhan harus lebih giat lagi dalam mengajak jemaat untuk ikut dalam doa puasa supaya spiritual jemaat bertumbuh. Dengan melihat latar belakang di atas maka penulis sangat mengharapkan supaya doa puasa dapat juga diutamakan sehingga bisa mempengaruhi pertumbuhan spiritual jemaat. Karena penulis melihat kondisi jemaat yang menjadi masalah jemaat untuk tidak datang dalam doa puasa adalah dikarenakan waktu dan kesibukan yang menjadi halangan. Masalah lain jemaat seringkali hanya melakukan puasa tanpa diserta doa dan hanya seberapa saja yang mengikuti kegiatan doa puasa ini. Itu tidak secara keseluruhan jemaat yang datang untuk melakukan doa puasa bersama di gereja.

\section{Pokok Masalah}

Berdasarkan latar belakang yang ditulis di atas, maka yang menjadi pokok masalah dalam penulisan skripsi ini adalah:

Pertama, apakah yang dimaksud dengan doa puasa baik secara umum maupun secara khusus dalam pemahaman Kristen?

Kedua, bagaimana pengaruh doa puasa bagi kehidupan di jemaat GKII Tanjung?

\section{Tujuan Penelitian}

Berdasarkan pokok masalah di atas, maka penulis menguraikan tujuan penulisan sebagai berikut:

Pertama, agar dapat diketahui sejauh mana pengaruh doa puasa yang dilakukan oleh gereja dalam kehidupan jemaat untuk membentuk pertumbuhan spiritualitas jemaat di Gereja Kemah Injil Indonesia Tanjung Belimbing Kalimantan Utara.

Kedua, agar setiap orang percaya dapat memiliki kerinduan untuk melakukan doa puasa secara rutin. Lewat doa puasa kita akan mengalami kuasa dari Allah sendiri.

\section{Manfaat Penelitian} berikut:

Beberapa manfaat yang ingin dicapai dalam penulisan skripsi ini adalah sebagai 
Pertama, supaya penulisan skripsi ini dapat memberkati dan menambah wawasan penulis serta pembaca.

Kedua, sebagai salah satu untuk memenuhi persyaratan akademik dalam menyelesaikan Stratum Satu (S-1) dalam program studi Theologi di Sekolah Tinggi Theologia Jaffray Makassar.

\section{Metode Penelitian}

Metode penelitian yang dipergunakan skripsi ini menggunakan metode kualitatif dengan teknik pengumpulan data dilakukan sebagai berikut:

Pertama, studi kepustakaan yaitu penulis membaca dan mengambil data dari bukubuku, jurnal dan internet yang berhubungan dengan judul sebagai penambah materi untuk memperoleh sumbangan pikiran, gagasan, dan ide-ide yang baru yang berguna untuk penyusunan skripsi.

Kedua, penulis mengadakan observasi langsung di lapangan, yaitu dengan cara wawancara dan membagikan angket secara tertutup yang disebarkan kepada jemaat di GKII Tanjung Belimbing Kalimantan Utara dengan tujuan mendapatkan data yang akurat tentang sejauh mana pengaruh doa puasa bagi pertumbuhan spiritual di jemaat GKII Tanjung Belimbing.

\section{Batasan Penelitian}

Dalam penulisan skripsi ini, penulis membatasi objek penelitian pada jemaat di GKII Tanjung Belimbing, Kabupaten Malinau, Propinsi Kalimantan Utara. Tentang bagaimana pengaruh doa puasa bagi pertumbuhan spiritual di jemaat GKII Tanjung Belimbing.

\section{Kesimpulan}

Pada bab ini, penulis memberikan kesimpulan dan saran-saran dari semua yang telah diuraikan dalam bab-bab sebelumnya yang berhubungan dengan kajian doa puasa bagi pertumbuhan spiritual. Berdasarkan hasil penelitian yang dilakukan oleh penulis, maka penulis memberi kesimpulan sebagai berikut:

Pertama, berdasarkan penelitian penulis, maka disadari bahwa doa puasa adalah komunikasi yang dilakukan antara orang percaya dengan Tuhan dan menfokuskan hati serta pikirannya kepada Tuhan dengan mampu menahan segala keinginan-keinginan daging. Oleh karena itu agar dalam jemaat GKII Tanjung Belimbing mau ikut melakukan doa puasa, maka terlebih dahulu harus mengerti dan memahami dengan baik apa yang dimaksud dengan doa dan puasa, karena doa puasa adalah tugas yang harus dilakukan oleh semua orang percaya tanpa terkecuali. Karena itu, maka doa puasa yang telah dilakukan di GKII Tanjung Belimbing perlu untuk diperhatikan lebih baik lagi mengingat ada dampak yang penting bagi pertumbuhan spiritual jemaat.

Kedua, dampak doa puasa merupakan salah satu bagian yang penting bagi orang Kristen yang perlu terus dilakukan di jemaat GKII Tanjung Belimbing. Karena itulah, maka penulis pun merasa bahwa hal ini harus dilakukan di dalam gereja ini yang menjadi tempat dibentuknya pertumbuhan spiritual dan disiplin rohani jemaat.

Ketiga, mengenai tantangan-tantangan yang dihadapi oleh jemaat dalam melakukan doa puasa, maka jemaat perlu mampu melawan setiap tantangan-tantangan dalam melakukan 
doa puasa dengan meminta hikmat dari Roh Kudus. Jelas bahwa tujuan semua pelaksanaan ini adalah untuk membangun pertumbuhan spiritual jemaat yang lebih baik lagi dalam mempersiapkan diri menghadapi setiap pergumulan hidup setiap jemaat dan dapat menjadi teladan dalam disiplin rohani.

Keempat, fungsi seorang dari hamba Tuhan menolong dan memberikan motivasi kepada jemaat untuk terus giat melakukan doa puasa. Karena kehidupan doa puasa seorang hamba Tuhan menjadi teladan yang kongkrit bagi jemaat. Maka penulis menyadari bahwa seorang hamba Tuhan memegang peranan penting dalam kehidupan spiritual jemaatnya.

Kelima, penting bagi orang Kristen melakukan doa puasa untuk pertumbuhan spiritual. Doa puasa melatih orang Kristen untuk dapat lebih mengandalkan Tuhan dalam kehidupan. Pentingnya doa puasa karena ini juga membina orang Kristen dalam disiplin rohani. Pembinaan harus dilakukan secara tahap demi tahap. Doa puasa adalah aspek terpenting bagi kehidupan kekristenan.

\section{Kepustakaan}

Anamofa,Jusuf Nikolas. "Studying Christian Spirituality.” Jurnal UNIERA 2 No. 2 (2013):144-151 Diakses 24 April 2018

http://journal.uniera.ac.id/pdf_repository/juniera54.BZ8msqCtCxIy8iYfYak1G9aB. pdf.

Bambarehi, Rosyanthi Ferayanthi \& Ivone Bonyadone Palar. "Formasi Rohani Seorang Pelayan Anak Dalam Penunjang Efektivitas Pelayanan”. Jurnal Jaffray 9, No. 2 (2011): 07-15. Diakses 20 Februari 2018.https://googleweblight.com/i?u=http://www.neliti.com/id/publication s/13741/formasi-rohani-seorang-pelayan-anak-dalam-menunjang efektivitaspelayanan\&hl=id-ID.

Bartlett, David L. Pelayanan Dalam Perjanjian Baru. Jakarta: BPK Gunung Mulia, 2011. Brill, J. Wesley. Doa-Doa Dalam Perjanjian Lama.Bandung: Kalam Hidup, 2005.

Brake, Andrew. Spiritual Formation: Menjadi Serupa Dengan Kristus. Bandung: Kalam Hidup, 2014.

Bullock, Hassell. Kitab Nabi-Nabi Perjanjian Lama. Malang: Gandung Mas, 2009.

Collins, Michael \& Matthew A. Price. The Story Of Christianity. Yogyakarta: Penerbit Kanisius, 2010.

Djadi, Jermia. “Spiritualitas Seorang Pelayan Tuhan.” Jurnal Jaffray 10, No. 1 (2012): 110117 Diakses 20 Februari 2018. http://www.academia.edu/7737384/Jurnal_Jermia_Djadi_6

Edwars, Jonathan. Pengalaman Rohani Sejati. Malang: Penerbit Momentum, 2011.

Foster, J. Richard. Tertib Rohani: Sudahkah Anda Menapakinya? Malang: Gandum Mas 1990.

Gondowijoyo, J. H. Membangun Keintiman dengan Bapa.Yogyakarta: Penerbit ANDI, 2011.

Hadiwijono, Harun. Pasrah Dalam Doa. Jakarta: Yayasan Komunikasi Bina,1986. 
Hartono, Chris. "Spiritualitas Calvinis.” Jurnal Duta Wacana 30 No.2 (2006): 1-10.

Diakses 23 April 2018,http://journal-

theo.ukdw.ac.id/index.php/gema/article/view/84/77.

Henry, Matthew. Tafsiran Matthew Henry: Injil Matius 1-14. Surabaya: Momentum, 2007.

Hull, Bill. Panduan Lengkap Pemuridan: Menjadidan Menjadikan Murid Kristus.

Yogyakarta: Yayasan Gloria, 2014.

Idu, Emmanuel. Radikal Untuk Tuhan. Jakarta: Harvest Publication House Divisi dari

Yayasan Pelayanan Tuaian Indoensia, 2000.

Karman, Yonky. Bunga Rampai Teologi Perjanjian Lama: Dari Kanon Sampai Doa. Jakarta: BPK Gunung Mulia, 2007.

Laukapitang, Yunus. Materi Penyelidikan Alkitab Doa dan Puasa. Makassar: Sekolah Tinggi Theologia Jaffray, 2017.

Mutak, Alfius Areng. "Spiritualitas Kristen Dan Krisis Finansial Global.” Jurnal Theologia Aletheia 11 No. 20 (2009): 21-39 Diakses 24 April 2018, http://sttaletheia.ac.id/wpcontent/uploads/2012/08/spritualitas-kristen-dan-krisis.pdf.

Moore, T. M. Disiplin Anugerah. Malang: Literatur SAAT, 2004.

Paterson, Robert M. Tafsiran Alkitab Kitab Imamat. Jakarta: BPK Gunung Mulia, 1994.

Pfeiffer, Charles F. \& Everett F. Harrison. Tafsiran Alkitab Wycliffe Vol.1. Malang:

Gandum Mas, 2004.

Prince, Derek. Doa Dan Puasa Menentukan Masa Depan. Jakarta: Yayasan Pekabaran Injil "Immanuel", 1995.

Roberts,G. Ajarlah Kami Berdoa. Jakarta: BPK Gunung Mulia, 2008.

Rowley, H. H. Ibadat Israel Kuno. Jakarta: BPK Gunung Mulia, 2004.

Sanders, Oswal. Kepemimpinan Rohani. Bandung: Kalam Hidup, 2005.

Scazzero, Peter. Emotionally Healthy Spirituality. Surabaya: Literatur Perkantas, 2014.

Singa rimbun, Masri \& Sofian Effendi. Metode Penelitian Survai. Jakarta: IKAPI, 1982.

Sugiyono. Metode Penelitian Kombinasi. Bandung: ALFABETA, 2014.

Sumadikarya, Kuntadi. Selusur Spiritual. Jakarta: Binawarga, 2007.

Sumanto. Metodologi Penelitian Sosial \& Pendidikan. Yogyakarta: ANDI, 1990.

Susanto, Hasan. Perjanjian Bari Interlinear Yunani Indonesia dan Konkordansi Perjanjian Baru Jilid II. Jakarta: Lembaga Alkitab Indonesia, 2002.

Tong, Stephen. Roh Kudus, Doa dan Kebangunan. Surabaya: Momentum, 2006.

Tozer, A. W. Jalan Menuju Kuasa Rohani. Bandung: Kalam Hidup, 2007.

Tu'u, Tulus. Pemimpin Kristen Yang Berhasil.Bandung: Bina Media Informasi, 2010.

Whitney, Donald S. Disiplin Rohani: 10 Pilar Penopang Kehidupan Orang Kristen.

Bandung: Lembaga Literatur Baptis, 1994.

Wijanarko, Jarot \& Toto Hadiriyanto. Roh Sukacita: Serial Pujian Penyembahan. Jakarta:

Suara Pemulihan, 2015.

Wijaya, Hengki (ed.). Metodologi Penelitian Pendidikan Teologi. Makassar: Sekolah

Tinggi Theologia Jaffray, 2016.

Winarno, S. Dasar Dan Teknik Research. Bandung: Tarsitu, 1978.

Yusuf, A. Muri. Metode Penelitian Kuantitatif, Kualitatif \& Penelitian Gabungan. Jakarta: Penerbit Kencana, 2017. 